This is an electronic reprint of the original article. This reprint may differ from the original in pagination and typographic detail.

Author(s): Paloviita, Ari

Title: $\quad$ Food processing companies, retailers and climate-resilient supply chain management

Year: $\quad 2015$

Version:

Please cite the original version:

Paloviita, A. (2015). Food processing companies, retailers and climate-resilient supply chain management. In A. Paloviita, \& M. Järvelä (Eds.), Climate Change Adaptation and Food Supply Chain Management (pp. 194-205). Routledge. Routledge Advances in Climate Change Research.

All material supplied via JYX is protected by copyright and other intellectual property rights, and duplication or sale of all or part of any of the repository collections is not permitted, except that material may be duplicated by you for your research use or educational purposes in electronic or print form. You must obtain permission for any other use. Electronic or print copies may not be offered, whether for sale or otherwise to anyone who is not an authorised user. 


\section{Chapter 16 - Food Processing Companies, Retailers and Climate-Resilient Supply Chain Management}

Ari Paloviita

University of Jyväskylä, Department of Social Sciences and Philosophy, P.O. Box 35, 40014 University of Jyväskylä, Finland; ari.paloviita@jyu.fi

\section{Introduction}

While most firms and supply chains have become familiar with the $\mathrm{CO}_{2}$ mitigation, less clear is their acquaintance with climate change adaptation and supply chain disruptions. Although the risks associated with climate change are recognised by many businesses, few firms are actively responding to those threats and deploying specific adaptation measures. West (2014) defines risk management as "the culture, processes and structures that are directed towards realising potential opportunities, while managing adverse effects". Here, two sides of climate change risk are acknowledged: potential opportunities and undesired impacts. Hence, building anticipatory adaptation and supply chain resilience to climate change deserves explicit attention in supply chain management.

Supply chain design should incorporate resilience (Leat and Revoredo-Giha 2013) as well as vulnerability assessment (Beermann 2011). Food supply chains are increasingly vulnerable to both extreme weather events and long-term climate change. Furthermore, economic, environmental and social impacts from gradual changes in mean climate conditions, greater climate variability and intense weather extremes are likely to increase in the future. Agriculture, the food processing industry, the retail sector and consumers are all affected by these impacts, directly or indirectly. Reducing greenhouse gas (GHG) emissions in the food supply chain is a necessary action, but building resilience to the already unavoidable climate-related impacts, which threaten food supply chains, is another task. For this chapter, supply chain adaptation is defined as longer-term, anticipatory adjustments to the observed or expected impacts of climate change, while supply chain 
resilience is defined as the adaptive capacity of the supply chain to absorb the impacts and to learn and to recover from external impacts.

Climate change adaptation and food supply chain management are examined from the perspective of food processing companies and retailers. From the food supply chain perspective, adaptation strategies and measures to climate change are heavily directed towards agriculture, with little emphasis on other phases of the food supply chain. The food processing industry and supermarkets have become the dominant players in the European food supply chains over the past 30 years (Bourlakis and Bourlakis 2004, 222). On the other hand, their success has been greatly dependent on their upstream supply chain relationships with their suppliers and downstream supply chain relationships with their customers and consumers. I begin with an overview of the key characteristics of the food supply chains in the European context. I then discuss supply chain risks, vulnerability to climate change, adaptation activities and food supply chain resilience. I conclude with a discussion of the value chain approach to climate change adaptation and the importance of partnerships with producers and consumers.

\section{Key characteristics of food supply chain}

\section{Global food industry and retail}

According to Ramsey (2000), the internationalisation of the food supply chains took place between 1945 and 1980, which was followed by globalisation phase. The globalisation of retailing is a relatively recent phenomenon, whereas food processing and manufacturing has had global characteristics for a long time. However, supply chain control has shifted from manufacturers to retailers in Europe and in the United States, where supermarket retailers are taking the lead (Bourlakis and Bourlakis 2004, 222; Marion 1998). The emergence of food retailers (supermarkets) as the dominant force in the food supply chain and the expansion of retailers across European borders is one of the key characteristics of structural change in the contemporary European food system (Fearne et al. 2001, 57). Hence, food sector enterprises have taken a global perspective on food supply chains when aiming for growth, speed and profitability. Increasingly large multinational food companies dominate the global food system, which can potentially lead to the "McDonaldization" of the food society (Ritzer 1993). International expansion - as an important growth strategy for food enterprises - forces companies to seek new markets in Latin America and 
Asia, as North America, Japan and Western Europe approach market saturation and population stagnation (Pullman and $\mathrm{Wu} 2012$, 185). As a consequence of global growth strategies, the global food system relies increasingly on industrialised production and centralised distribution networks. On the other hand, globalised food supply chains have enabled consumers to have year-round access to almost any food product.

\section{Concentration and consolidation of food industries and retailers}

National grocery markets, especially in Northern Europe, are characterised by a high level of concentration as the balance of power has shifted to favour food retailers (Fearne et al. 2001, 63). In fact, concentration and consolidation in the food industry is increasing all over the world. However, the EU agricultural policy seems to favour small-scale farming, although other segments of the food system are shifting to large-scale production and delivery. In contrast, US agricultural policy favours large-scale farming and food processing (Pullman and $\mathrm{Wu}$ 2011, 253). According to Pullman and $\mathrm{Wu}(2011,253-254)$ there are five major negative effects of food system consolidation: 1) power concentration affects the terms of supplier contracts, e.g. low supplier pricing; 2) consolidated food companies have an influence on food policies, e.g. GMO policy; 3) concentrated production facilities have negative impacts on health, animal well-being and the quality of life in communities e.g. by eliminating local small competitors; 4) consolidation requires more organised suppliers meet the minimum volumes, e.g. full truck shipments; 5) the low consumer pricing of consolidated companies may not last, e.g. price fixing. In Europe, the market share of the top three food retailers ranges typically from 30\% to 50\% (FoodDrinkEurope 2013). However, in Ireland, Sweden and Denmark it is above 70\%. The most concentrated retail sector is in Finland, where two retailers, S-group and K-group, dominate nearly $80 \%$ of the national grocery market. According to FoodDrinkEurope (2013), countries with a higher food retail concentration tend to experience a high level of private label penetration. Hence, private label selling arrangements between large retailer groups and food processing companies/manufacturers are becoming more common in Europe. In Finland, the market share of private label food products is nearly 25\% in S-group and 80\% in Lidl (Talouselämä 2013).

\section{Food cooperatives}

Food cooperatives play a significant role in Europe, both in mainstream and alternative food supply chains. The continued existence of food cooperatives affects the supply chain dynamics in terms of upstream and downstream supply chain relationships. In food supply chains the cooperatives are typically producer-owned or consumer-owned cooperatives. In many European countries there are 
very large producer-owned cooperatives, especially in dairy, meat and input supplier industries. In many countries the majority of the meat and milk produced by farmers is collected by cooperatives. The turnover of the largest producer-owned cooperatives ranges from 1-10 billion euros. There are also large-scale cooperatives in the wine, fruit and vegetable sectors. For example, according to the German Cooperative and Raiffeisen Confederation, almost all German farmers, gardeners and winegrowers as well as $90 \%$ of all bakers and butchers are members of a cooperative. Europe's largest producer-owned cooperatives can be found in the Netherlands, Denmark and Germany. The highest cooperative membership intensity (more than 80\%) can be found in the Netherlands, Greece, France, Germany, Ireland and Finland. Very high membership intensity (50-80\%) also exists in Denmark, the UK, Belgium and Austria (Preusse 2013; Cogeca 2010; Corneros Reguero 2013; DGRV 2014).

In addition, consumer cooperatives retain a significant market share in food retail in many European countries, especially in Finland, Scandinavia, the UK, Ireland, Italy and France. The largest food wholesaler/retailer in Finland, S-group, is a cooperative with a market share of $46 \%$ in the Finnish food retail markets. The regional cooperatives of The S-Group are owned by co-op members and supported by the Finnish Cooperative Wholesale Society (SOK). In addition, there is a broad variety of alternative cooperatives for farmers as well as consumer-owned food co-ops, which have specialised, for example, in locally produced food and organic food.

\section{Small and medium-sized food companies}

Although the global food industry is increasingly centralised, 99\% of the food enterprises are small and medium-sized companies (SMEs) (FoodDrinkEurope 2013). In addition, micro-companies (less than 10 employees) typically represent more than half of the all food enterprises. In France, the distribution of micro-companies to total companies is $90 \%$. Both the US and European food systems have developed a bimodal distribution concentration, which means that larger firms are increasingly larger, while the number of smaller firms has increased (Rogers 2001). SMEs operate mainly locally and regionally. Hence, SMEs are the key actors in local and regional food systems, which can include different types of alternative food supply chains. While the largest companies seek economies of scale through vertical integration in food distribution and an increase in the amount of diverse customer segments with a mass market orientation, the food supply chains of SMEs are typically shorter, more transparent and focused on niche marketing strategies based on local, regional, traditional and seasonal food products (Rogers 2001; Hughes 2004, 109-112). According to Pullman \& Wu $(2012,256)$, the diversity of the food system, i.e. diverse agricultural 
production, small-scale processing and small-scale distribution, creates resilience, allowing it to adapt to climate change, policy change and resource issues.

\section{Climate change adaptation in food supply chains}

\section{Risks and supply chain vulnerability}

Food supply chain risks resulting from climate change can be assessed locally, regionally, nationally or globally. Most of the food processing companies operate locally or regionally using mainly local or regional suppliers and by selling their products to local or regional customers. Hence, within their relatively short supply chains, assessing local or regional vulnerability to climate change is their primary concern. The largest food processing companies have national supply networks, which are often complemented by global sourcing networks. Their main concern is supply chain vulnerability at the national level, but they are also affected by the risks occurring in global supply chains. Large retailers are actively involved in long, interdependent networks of global supply chains, which can be undermined by different types of threats and can be very vulnerable regarding climate change (Beermann 2011). Hence, overcoming vulnerabilities in the global supply chain is critical for them.

There are both physical and regulatory risks associated with climate change for food processing companies and retailers. In addition, there are financial risks, litigation risks, reputational risks and competitive risks involved (Nitkin et al. 2009, 18). Physical risks in the food supply chain are mostly faced by primary production and agriculture because their activities are directly affected by the weather and climate conditions. Extreme weather events may have catastrophic effects on local farms, communities and infrastrucutre. In addition, disruptions in the supply of agricultural raw materials may have serious consequences along the whole of a food supply chain. Long-term gradual changes in the climate are more difficult to observe and the risks from these gradual changes can grow over time without immediate warning signals. In addition to agriculture, the energy sector is a critical factor in the food supply chain, but its position in terms of climate change adaptation is complex. However, disruptions in energy supply in agricultural production, food processing and manufacturing as well as in transportation and retailing pose a serious risk to all 
supply chain operations. Furthermore, water supply is necessary for most of the food supply chain operations and any permanent shifts in water supply should be addressed by the companies.

\section{Adapting to climate change and building resilience}

Climate change adaptation in the food supply chain can be thought of as part of the continual process of risk or resilience management by food processing and retailing firms. However, adapting their behaviour so that it becomes economical and sustainable is a slow process, especially as the benefits of climate change adaptation may take decades to take effect. As the majority of the food processing companies and manufacturers are small firms, their overall awareness of the extent of the required adaptation may be vague. The general assumption is that SMEs are more vulnerable to climate shocks, but are not prepared for the impacts of climate change (West 2014, 240). SMEs simply do not have the resources to conduct vulnerability assessments or other relevant measures. On the other hand, large retailers in the food supply chain may consider climate change adaptation a marginal activity as the direct risks of climate change occur elsewhere in the supply chain.

Sheffi (2005) suggests that companies can develop resilient supply chains by increasing redundancy, building flexibility or changing corporate culture. It is easy to agree with Sheffi that building flexibility and changing corporate culture are essential, whereas redundancy has a limited utility. In the food supply chain, redundancies can be built, for example, by holding an extra food inventory and by having many food suppliers. Redundancy, however, can be counterproductive to efficiency (Sheffi 2005).

Aligning procurement strategy with supplier relationships is one of the key actions in developing built-in flexibility (Sheffi 2005). A company can either rely on a small group of key suppliers with deep relationships, or it can have an extensive supplier network of arm's length suppliers with shallow relationships. The majority of food processing companies, i.e. small companies, naturally have a relatively small group of suppliers, which they know intimately and which can be monitored rather easily. Large food processing companies rely either on a limited group of contract suppliers or more extentisive supplier networks. Retailers have a tradition of using extensive supplier networks with arm's length relationships. Companies with a small group of local suppliers or a limited group of contract suppliers are more knowledgeable about their partners as well as the risks and vulnerabilities involved in the relationships compared to companies with an extensive supplier 
network. Thus, achieving full knowledge of supply chain disruptions and other risks related to climate change is very much dependent on supply chain relationships.

Along the downstream supply chain, building resilience requires cultural change, including continuous communication among employees, empowerment, cultural values and flexibility (Sheffi 2005). Hence, the ability to manage cultural change will distinguish resilient companies from other companies. According to Pullman and Wu (2012, 256), regional food supply chains typically emphasise the importance of communities, fair wages, trustworthy relationships and equitable power structures, which can be seen as the cornerstones of cultural resilience. Problems arise, when supply chains become longer and information flows are interrupted by intermediate actors. The European horse meat scandal in 2013 demonstrated information interruption in a food supply chain and the weaknesses of an increasingly globalised food supply chain: food processing companies and manufacturers were not able to monitor their suppliers accurately and horsemeat was used in products sold as beef. As a result, global food supply chains are now expected to strengthen the capability of their control systems to assess the potential vulnerabilities of the different parts of the supply chain (DG health and consumers 2014).

\section{Value-chain approach to climate change adaptation}

\section{Partnerships with producers}

The vulnerability of small farms to climate change can put entire food supply chains at risk. For example, climate change will alter the relative productivity of various regions and affect input costs (Porter and Reinhardt 2007). Hence, the geographical location of a farm is crucial with respect to its exposure and sensitivity to climate change. There is a growing global network of interational suppliers from various locations with higher exposure and sensitivity to climate change. A strategic approach to climate change requires comprehensive vulnerability assessments, which should be conducted either by food processing companies or by large sourcing and logistics companies supporting retailers.

Buyers in the food supply chain, i.e. food processing companies and manufacturers as well as wholesalers and retailers, are better positioned relative to primary suppliers, i.e. farms, to meet climate change risks. Firstly, buyers and intermediaries can easily substitute their suppliers. For 
example, outsourcing raw material production makes a food supply chain more flexible especially if the productivity of various regions declines (Porter and Reinhardt 2007). Food manufacturers or retailers may even relocate the hub of a supply chain away from an area that is overly exposed to extreme weather events (West 2014). Secondly, regarding rigid supply structures, such as those based on contract relationships, the food industry and retailers can use their negotiating power with small farms. On the other hand, alternative food supply chains can emerge if the most powerful supply chain players misuse their institutionalised power. In many ways, the considerable adaptive capacity of retailers makes them the most resilient actor in the food supply chain. However, the extent to which food processing companies and retailers are dependent on farmers to supply food inputs for downstream value-adding processes is the key determinant of their vulnerability to climate change (Benedikter et al. 2011). Therefore implementing climate resilience action in partnership with farmers may be framed in win-win terms because they emphasise long-term benefits for both supply chain partners. These partnerships can include both vertical and horizontal collaboration (Leat and Revoredo-Giha 2013).

Farmers clearly need to change to increase their adaptive capacity and decrease their vulnerability to climate change. Besides climate change risks, farmers are facing various economic and regulative risks, which have consequences for their welfare and livelihood. Food processing companies and retailers do not need to change as urgently as farmers. However, they are the food supply chain actors who could facilitate change in terms of adaptation to climate change along whole supply chains. By building food value chains based on long-term strategic partnerships with producers, the food industry and retailers, climate change adaptation could be tailored to specific situations and the needs of populations. This obviously needs to be supported by the provision of incentives and assistance from relevant institutions, governments and third-party organisations (Leat and Revoredo-Giha 2013).

Exploiting the vulnerabilities of others decreases trust and mutual confidence in the supply chain. As farmers can easily become victims of the policies of more powerful supply chain actors (see e.g. Benedikter et al. 2011), it is crucial that rights and responsibilities - with respect to climate change adaptation - are balanced in the food value chains by sharing information on climate change risks and its potential effects as well as by implementing risk-sharing protocol, shared governance structures and shared decision-making (see e.g. Stevenson and Pirog 2008). 
Local communities and regions hold local and regional data and information that is critical for helping food processing companies and retailers undertake vulnerability assessments (Amado and Adams 2012). On the other hand, food processing companies and retailers have more comprehensive data on supply chain performance and the full lifecycle impacts. The hotspots for risks in a supply chain can be identified by sharing information with other supply chain members. Also, information on adaptation costs should be shared along with other economic information and data, e.g. the true cost structures of production and transaction costs. According to Liverman and Ingram (2010, 204), regions make sense in terms of environmental change, e.g. climate and weather-related perturbations, because the physical coherence of regions enables environmental and food system data collection at the regional level.

Climate change risks are not evenly distributed in the food supply chain, as farmers face the most direct risks that can disrupt a supply chain. As farm-level and community-level risks are also supply chain risks, risk-sharing protocol should be a part of the collaborative partnership. At the regional level, improved intraregional trade, strategic food reserves and transport facilities can enhance food security (Liverman and Ingram 2010, 205).

Proactive governance refers to assistance, which is provided to value chain participants in meeting legislative ethical, environmental and social standards for supply chains (Kaplinsky 2000). In a food supply chain, large processing companies, manufacturers and retailers could decrease the vulnerability of supply chains by providing assistance to their supplier farms and communities in the form of increasing their adaptive capacity at local and regional level. According to Liverman and Ingram (2010, 205), food security and environmental interaction should be considered at the regional level due to the emergence of regional governance. Hence, shared governance structures might be more suitable for regional food supply chains than for global supply chains.

Shared decision-making in the food value chain should be based on fairness and justice, including adequate profit margins above production costs and the predictability of agreements among partners (Stevenson and Pirog 2008). Climate change adaptation is a slow process and requires commitments to long-term investment for adaptive capacity and resilience. 
Changes in demand and in societal and cultural preferences were identified as a potential indirect climate change risk in a German study on the corporate climate adaptation strategies of the food industry (Beermann 2011). For example, changes in eating habits and demand for certified products were identified as the potential indirect impacts of climate change. Adaptation to climate change in the food supply chain ultimately depends on what consumers want and how their behaviour and practices change. However, the complexity of the food supply chain and a lack of supply chain transparency may increase the vulnerability of consumers and hinder adaptive behaviour and practices. The behaviour and practices of consumers regarding their consumption and postconsumption behaviour, e.g. waste management, will be a key feature of their adaptive capacity. Promoting climate-resilient diets and food choices as well as minimising the adverse impacts of food waste can enhance the resilience of whole supply chains. Food processing companies and retailers could find opportunities related to climate-resilient food products and climate-resilient food markets. Moreover, reverse logistics management could enhance closed-loop food supply chains through the better utilisation of food waste.

Consumer vulnerability is a concept, which reflects a state of powerlessness arising from an imbalance in marketplace interactions or from the marketing messages and products (Baker et al. 2005). Modern, concentrated food supply chains may indeed increase the dependancy of consumers on external factors, such as the food industry and large super- and hypermarkets. Urban consumers have very little control over the food supply chain, which may increase their feelings of vulnerability. A consumer response to this experienced vulnerability is adaptation, which includes positive behavioural and emotional coping strategies (Baker et al. 2005). However, unlike farmers in food production, the majority of the consumers in Western Europe are not used to coping with vulnerabilities in food consumption. For example, the last real vulnerability test for Finnish consumers was experienced during World War II, when national food rationing came into force. After the 1950s Finnish consumers, like most western European consumers, have become less selfreliant and more dependent on industrialised and globalised food systems. In practice, contemporary consumers live from hand to mouth because only a few consumers have the capacity to grow food themselves or have storage capacity, such as a chest freezer or root cellar that can help them survive winter.

Some consumers have adopted a coping strategy for alternative food supply chains. Communitysupported agriculture (CSA) is the latest alternative trend in Europe. In CSA, consumers make an economic commitment by buing a share in a farm, which produces food for them. Consumers also 
share the risks related to farming, for example, losses caused by weather events. There are 10000 CSA farms in the US, 1600 CSA farms in France, but only 13 CSA farms in Finland, where this business model is still in its infancy (Helsingin Sanomat 2014). In addition, consumers have opportunites to join the food cooperatives and food circles of the cities, which distribute locally produced food directly from farms to consumers.

Alternative food supply chains represent a very marginal supply chain model compared to retaildriven and food industry-driven conventional supply chains. Hence, in the current food system, food processing companies, manufacturers and retailers are the key players for partnering consumers in the building of resilient food supply chains. A food processing company or manufacturer is responsible for value chain governance in the upstream supply chain. For example, they need to be informed about potential environmental, social or ethical risks in food production. From a consumer vulnerability point of view, sharing information about supply chain risks with consumers is critical. Food packaging information is an important element in communication but insufficient for informing consumers about supply chain vulnerabilities or resilience. Partnerships between the food industry and consumers may be built in collaboration with consumer associations or community groups. The goals of these partnerships can include, for example, increasing the extent of consumer knowledge about agriculture and the rural environment, demonstrating the complexity of the food supply chain and distributing the results of supply chain vulnerability assessments. In other words, the main aim is to increase trust and mutual confidence in the food supply chain.

Vertical collaboration between retailers and food processing companies/manufacturers is crucial not only in terms of business transaction, but also for enhancing resilient relationships between procesessors and retailers. Hence, from the relationship management point of view, social psychology can provide useful approaches for healthy and resilient relationships. From the perspective of information management, information on vulnerabilties in the upstream supply chain should flow smoothly from industrial actors to retailers. In some product groups, upstream supply chain governance regarding vulnerabilities and resilience should be managed by retailers. Supply chains for fresh fruits and vegetables, for example, do not include a separate processing or manufacturing phase. The vulnerability of the banana or pineapple supply chain should be monitored and assessed by retailers or their sourcing and logistics companies. 
On the other hand, retailers are increasingly investing in local and regional food supply chains with local and regional farmers and processors. Direct relationships with producers will help retailers to learn about local and regional conditions for production, including climate-related issues. In addition, retailers are increasingly aware of the need to develop value-added and knowledge-added lines to support the consumers' perception of quality (Marsden et al. 2000). As part of climate change adaptation, partnerships between retailers and consumers should promote knowledgesharing and learning about risks and opportunites in the supply chain in order to decrease the experience of vulnerability that consumers may feel.

\section{Conclusion}

Climate change risk is only one of a wide range of risks the food supply chain is exposed to. Hence, climate change risk and climate change adaptation should be seen as part of a much broader risk management framework that takes into account various vulnerabilities in the food supply chain. A value chain approach could provide win-win benefits for supplier farms, food processing companies, retailers and consumers. This requires information-sharing, risk-sharing, shared governance and shared decision-making via partnerships. In Europe, food processing companies and retailers should be able to identify vulnerabilities on the local, regional, national and global supply chain levels in order to define the goals and scope for climate change adaptation. Iterative processes of transformational adaptations or long-term adjustments towards resilience require different types of changes in organisations. To achieve that, structural change in organisational logic, cultural change and most of all change in adaptive behavior are required to facilitate continual organisational learning processes regarding risks and vulnerabilities. Furthermore, changes in social practices, institutions, cultural values and knowledge systems may promote social and technological innovations for climate change adaptation. One of the key outcomes of a climate-resilient food supply chain management should be the building of trust between suppliers, buyers and consumers as well as the resilience of supply chain relationships. Hence, food processing companies, manufacturers, wholesalers and retailers need to redefine their relationships with farmers and consumers to enable food supply chain empowerment that can proactively respond to climate change.

\section{Acknowledgements}


This research was funded by Academy of Finland through the project A-LA-CARTE (decision no 140870) and by Kone Foundation through the research project "Future Food Security in Finland".

\section{References}

Amado J-C and Adams P 2012 Value chain climate resilience: A guide to managing climate impacts in companies and communities (http://www.oxfamamerica.org/static/oa4/valuechainclimateresilience.pdf) Accessed 18 June 2014

Baker S M Gentry J W and Rittenburg T L 2005 Building understanding of the domain of consumer vulnerability Journal of Macromarketing 25(2) 128-139

Beermann, M 2011 Linking corporate climate adaptation strategies with resilience thinking Journal of Cleaner Production 19 836-842

Benedikter A Läderach P Eitzinger A Bunn C and Cook C 2011 Adaptation framework: Adaptation of food supply chains to the impacts of progressively changing climate (http://dapa.ciat.cgiar.org/wp-content/uploads/2011/07/Adaptation-Framework-Report.pdf) Accessed 18 June 2014

Bourlakis C and Bourlakis M 2004 The future of food supply chain management in Bourlakis M A and Weightman P W H eds Food supply chain management Blackwell Publishing, Oxford

Cogeca 2010 Agricultural cooperatives in Europe: main issues and trends (http://www.agroalimentarias.coop/ficheros/doc/03020.pdf) Accessed 31 October 2014

Corneros Reguero E M 2013 The case of Hojiblanca Options Méditerranéennes 106 111-116

DG health and consumers 2014 Horse meat: one year after - Actions announced and delivered (http://ec.europa.eu/food/food/horsemeat/) Accessed 4 November 2014

DGRV 2014 The German cooperatives in Europe (https://www.dgrv.de/webde.nsf/272e312c8017e736c1256e31005cedff/2e65c54b0c6567d6c12577c b0046b705/\$FILE/Cooperatives_EU.pdf) Accessed 31 October 2014

Fearne A Hughes D and Duffy R 2001 Concepts of collaboration: supply chain management in a global food industry in Eastham J F, Sharples, L and Ball S D eds Food supply chain management: Issues for the hospitality and retail sectors Elsevier, Oxford 
FoodDrinkEurope 2013 Data \& trends of the European food and drink industry 2012 (http://www.fooddrinkeurope.eu/publication/data-trends-of-the-european-food-and-drink-industry/) Accessed 31 October 2014

Helsingin Sanomat 2014 Mikä ihmeen CSA? (http://www.hs.fi/kotimaa/Mik\%C3\%A4+ihmeen+CSA/a1401424695200) Accessed 19 June 2014

Hingley M Mikkola M Canavari M Asioli D 2011 Local and sustainable food supply: The role of European retail consumer co-opertatives International Journal of Food System Dynamics 2(4) 340356

Hughes D 2004 Food manufacturing in Bourlakis M A and Weightman P W H eds Food supply chain management Blackwell Publishing, Oxford

Kaplinsky R 2000 Spreading the gains from globalisation: What can be learnt from value chain analysis? Brighton, IDS working paper 110, Institute of Sussex

Leat P and Reveredo-Giha C 2013 Risk and resilience in agri-food supply chains: The case of the ASDA PorkLink supply chain in Scotland Supply Chain Management 18/2 219-231

Liverman D and Ingram J 2010 Why regions? in Ingram J, Ericksen P and Liverman D eds Food security and global environmental change Earthscan, Oxon

Marion B W 1998 Changing power relationships in US food industry: brokerage arrangements for pivate label products Agribusiness 14 85-93

Marsden T Banks J Bristow G 2000 Food supply chain approaches: Exploring their role in rural development Sociologia Ruralis 40 424-438

Nitkin D Foster R and Medalye J 2009 Business adaptation to climate change: A systematic review of the litarature Network of Business Sustainability (http://nbs.net/wpcontent/uploads/NBS_Systematic-Review_Climate-Change.pdf) Accessed 18 June 2014

Porter M E and Reinhardt F L 2007 A strategic approach to climate Harward Business Review October $200722-26$

Preusse T 2013 In the spotlight: cooperatives Agrifuture autumn/13, 18-19

Pullman M and Wu Z 2012 Food supply chain management: Economic, social and environmental perspectives Routledge, New York 
Ramsey B 2000 (ed) The global food industry: Strategic directions Financial Times Retail and Consumer Publishing, London

Ritzer G 1993 The McDonaldization of society Pine Forge Press, Newbury Par, CA

Rogers R T 2001 Structural change in US food manufacturing, 1958-1997 Agribusiness 17 3-32

Sheffi Y 2005 Building a resilient supply chain Harvard Business Review 1(8) 1-4

Stevenson G W and Pirog R 2008 Values-based food supply chains: Strategies for agri-food enterprises-of-the-middle in Lyson T A Stevenson G W and Welsh R eds Food and the mid-level farm: Renewing an agriculture of the middle MIT Press, Cambridge MA 119-143

Talouselämä 2014 Kotimaisuus tuli kaupan merkkeihin (http://www.talouselama.fi/uutiset/kotimaisuus+tuli+kaupan+merkkeihin/a2241285) Accesssed 18 June 2014

West J 2014 The long hedge: Preserving organizational value through climate change adaptation Greenleaf Publishing, Sheffield UK 